\title{
Optical coherence tomography as a non-invasive method of enamel thickness diagnosis after orthodontic treatment by 3 different types of brackets
}

\author{
Monika E. Machoy ${ }^{1, A-F}$, Robert Koprowski $2, B, C, E, F$, Liliana Szyszka-Sommerfeld ${ }^{3, B, F}$, \\ Krzysztof Safranow ${ }^{4, C, F}$, Tomasz Gedrange ${ }^{5, E, F}$, Krzysztof Woźniak ${ }^{3, A, E, F}$ \\ ${ }^{1}$ Division of Orthodontics, Pomeranian Medical University in Szczecin, Poland \\ ${ }^{2}$ Department of Biomedical Computer Systems, Faculty of Computer Science and Materials Science, Institute of Computer Science, University of Silesia, Sosnowiec, Poland \\ ${ }^{3}$ Division of Orthodontics, Pomeranian Medical University in Szczecin, Poland \\ ${ }^{4}$ Department of Biochemistry and Medical Chemistry, Pomeranian Medical University in Szczecin, Poland \\ ${ }^{5}$ Division of Orthodontics, Technical University Dresden, Germany
}

A - research concept and design; B - collection and/or assembly of data; $C$ - data analysis and interpretation;

$D$ - writing the article; $E$ - critical revision of the article; $F$ - final approval of the article

Address for correspondence

Monika E. Machoy

E-mail:m.machoy@gmail.com

\section{Funding sources}

None declared

Conflict of interest

None declared

Received on August 23,2017

Reviewed on September 13, 2017

Accepted on November 8, 2017

Published online on July 26, 2018

Cite as

Machoy ME, Koprowski R, Szyszka-Sommerfeld L, Safranow K, Gedrange T, Woźniak K. Optical coherence tomography as a non-invasive method of enamel thickness diagnosis after orthodontic treatment by 3 different types of brackets. Adv Clin Exp Med. 2019;28(2):211-218. doi:10.17219/acem/79974

DOI

10.17219/acem/79974

Copyright

Copyright by Author(s)

This is an article distributed under the terms of the

Creative Commons Attribution Non-Commercial License

(http://creativecommons.org/licenses/by-nc-nd/4.0/)

\begin{abstract}
Background. Medical digital imaging is the basis of effective medical diagnosis and is now in the mainstream of a dynamically developing branch of science. Optical coherence tomography (OCT) enables real-time in situ imaging of tissues without the need for biopsy, histological procedures or X-rays.

Objectives. The aim of the study was to evaluate the application of OCT in orthodontic diagnostics and clinical practice by assessing the thickness of the enamel before and after orthodontic treatment.

Material and methods. A hundred and eighty teeth in this in vitro study were divided into 3 groups of 60 teeth each. In each group (Group 1 - metal brackets, Group 2 - ceramic brackets and Group 3 - composite brackets), the orthodontic brackets were attached to the enamel using the $5^{\text {th }}$-generation adhesive system. The image of the enamel tissue was captured with a 3D-OCT camera before installing orthodontic brackets and after debonding and mechanical processing. The obtained OCT scans were subjected to expert IT analysis. For the statistical analysis, the Shapiro-Wilk test, the median test, the Mann-Whitney U test, Friedman two-way analysis of variance (ANOVA), Wilcoxon matched pairs signed ranks test, the $x^{2}$ test of independence with Yates's correction, and Fisher's exact test were used. Maxwell's general principle was followed when using this type of test. The level of significance was set at $p=0.05$.
\end{abstract}

Results. The thickness of the enamel varied least when metal brackets were used. The changes in enamel thickness in the composite and ceramic bracket groups were not statistically significant.

Conclusions. Optical coherence tomography is an effective diagnostic tool to evaluate the thickness of the enamel tissue before and after orthodontic treatment. Changes in the enamel layer thickness after orthodontic treatment are determined by the type of material which the orthodontic bracket is made of.

Key words: tomography, optical coherence, orthodontics, optical coherence tomography, enamel 


\section{Background}

The concept of tomography refers to a method that provides images showing sections of the tested structure. The $1^{\text {st }}$ CT scanner, constructed in 1967, initiated the rapid development of medical imaging. A common feature among the different types of CT devices is the noninvasive imaging of tissue structures and internal organs. The desire to minimize invasive methods, such as biopsy or exploratory surgery, which are painful and may cause deterioration in the patient's condition, was the impetus for the improvement of CT equipment. As a result, completely new technologies were developed, such as magnetic resonance imaging (MRI), ultrasonography (USG), positron emission tomography (PET), single photon emission computed tomography (SPECT), and the latest and more widely used optical coherence tomography (OCT).

The method of OCT using interferometry with partially coherent light was first presented in 1991 at the Massachusetts Institute of Technology (MIT), Cambridge, USA. ${ }^{1}$ The $1^{\text {st }}$ in vivo measurements of the section of the human retina were made 2 years later in Vienna, Austria. ${ }^{2}$ The $1^{\text {st }}$ commercial optical tomography device was produced in 1996 by Zeiss-Humphrey. ${ }^{3}$

Optical coherence tomography provides images of the sections of tissues in a non-contact and non-invasive manner. The device measures the time delay and intensity of the light scattered or reflected from biological tissues, which results in tomographic imaging of their internal structure. This is achieved by scanning tissues at a resolution ranging from 1 to $15 \mu \mathrm{m}$. Optical coherence tomography enables real-time in situ imaging of tissues without the need for biopsy, histological procedures or X-rays, so it can be used in many fields of medicine. Its properties are particularly used in ophthalmology - in the diagnosis of all layers of the retina - but also increasingly in cardiology, gastroenterology, pulmonology, oncology, and dermatology.

The latest studies focus primarily on the early diagnosis of caries, the assessment of dental fillings, and the evaluation of periodontal and mucosal tissues and tooth structure. ${ }^{4-13}$

\section{Objectives}

In this article, we illustrated the application of OCT in orthodontic diagnostics and clinical practice by assessing the thickness of the enamel before and after orthodontic treatment. This method has a great impact on the proper treatment and choice of material and is already used by us. The possibility of appraising the enamel state and thickness enables the correct selection of the adhesive materials and type of bracket. Therefore, it should be introduced widely for clinical practitioners.

\section{Material and methods}

The study was carried out in an in vitro environment. The material comprised 180 teeth, divided into 3 groups of 60 teeth each. In each group, the orthodontic brackets were attached to the tooth surface using the $5^{\text {th }}$-generation adhesive system that uses the classic method of enamel etching with orthophosphoric acid. In the $1^{\text {st }}$ group, steel orthodontic brackets were used. The $2^{\text {nd }}$ group had ceramic brackets attached, while the $3^{\text {rd }}$ group was given composite brackets.

The experiment was carried out on premolars, extracted for orthodontic and periodontal reasons. The exclusion criteria were defined by the following conditions: the presence of developmental defects of enamel, i.e., hypoplasia, turbidity or discoloration (which is a symptom of caries), and fillings on the vestibular surface.

The teeth which qualified for research were stored for 30 days in demineralized water with a crystal of thymol $(0.1 \%)$ at room temperature. Before fastening orthodontic brackets, the tooth surface was cleaned using a polisher (TopDental, Bielsko-Biała, Poland) with fluoride-free toothpaste, Pressage (Shofu Inc., Kyoto, Japan), designed to prepare the enamel before fastening orthodontic brackets. Then, the teeth were washed with distilled water and dried with compressed air for $15 \mathrm{~s}$. For fastening orthodontic brackets, an orthodontic composite material, Transbond ${ }^{\mathrm{TM}}$ XT Light Cure Adhesive (3M Unitek, Diegem, Belgium), was used.

In the $1^{\text {st }}$ group, the vestibular surface of the tooth was etched for $30 \mathrm{~s}$ with a $37 \%$ solution of phosphoric acid - Blue-Etch (Cerkamed, Stalowa Wola, Poland) - rinsed with distilled water for $15 \mathrm{~s}$, and dried using compressed air. The adhesive system OptiBond Plus Solo (Kerr, Orange, USA) was rubbed with an applicator into the etched enamel surface for $15 \mathrm{~s}$, then the surface was dried under a gentle stream of air for $3 \mathrm{~s}$ and cured with a halogen lamp with a light intensity of $750 \mathrm{~mW} / \mathrm{cm}^{2}$ for $20 \mathrm{~s}$. The orthodontic composite material Transbond ${ }^{\mathrm{TM}}$ XT Light Cure Adhesive was applied to the bracket surface. The bracket was pressed against the enamel surface with common tweezers. The orthodontic bracket was placed in the middle of the mesial-distal axis of the tooth, moving its center $3.5 \mathrm{~mm}$ away from the edge of the occlusal surface. The distance was measured using an orthodontic positioner. After the proper placement of the bracket, the material was subjected to polymerization with a halogen lamp for $40 \mathrm{~s}$.

In the $2^{\text {nd }}$ group, the self-etching adhesive system G-Bond (GC, Tokyo, Japan) was used. The self-etching primer was left for $10 \mathrm{~s}$ after being applied to the tooth surface using an applicator, and then the excess was removed via an air stream for $5 \mathrm{~s}$. After this time, the system was polymerized with a halogen lamp with a light intensity of $750 \mathrm{~mW} / \mathrm{cm}^{2}$ for $20 \mathrm{~s}$. The orthodontic composite material Transbond ${ }^{\mathrm{TM}}$ XT Light Cure Adhesive was applied to the surface of the hook. The orthodontic hook was placed onto the tooth 
surface using the method described above. The teeth with the fixed orthodontic brackets were stored in demineralized water at room temperature for $24 \mathrm{~h}$. After this time, the hooks were removed mechanically with ix 827 pliers (DB Orthodontics Ltd, Silsden, UK), designed for removing all types of brackets. Residues of the adhesive material were removed from the enamel surface using a cemented carbide milling cutter - H390.204 AGK (Komet URPOL, Kędzierzyn-Koźle, Poland) - which has 8 notches, a length of $3.6 \mathrm{~mm}$, and a diameter of $0.1 \mathrm{~mm}$. The enamel was processed with the use of a micromotor commonly mounted to a dental unit at a speed of 40,000 rpm with water cooling and a pressure force of $1.0 \mathrm{~N}$. The force was measured on a test stand consisting of scales, on which the processed tooth was placed. The procedure of cleaning the enamel was considered to be finished based on a naked-eye examination and by touching with a $23-\mathrm{cm}$ stylet under the dental unit light. The assessment criteria were the smoothness of the tooth surface and the absence of the composite material residues. Tooth scans were performed using 3D-OCT tomography. The area of the test teeth was imaged with a 3D-OCT camera (Topcon, Las Vegas, USA) (Fig. 2) in 2 modes T0, imaging of the tooth surface before installing orthodontic brackets, and T1, imaging of the tooth surface after debonding and mechanical processing. Each time, 2-dimensional scans were performed, allowing

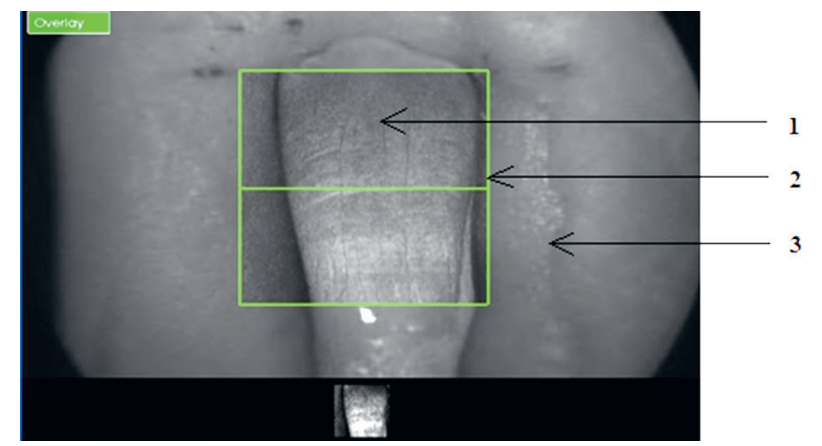

Fig. 1. 1 - extracted central lower incisor, captured using a digital camera with the resolution of 16.2 Mpix; coupled with tomography; 2 - window of the scanning area; 3 - the silicone matrix made for repeatable tooth positioning in the frontal, sagittal and horizontal plane relative to the optical axis of the optical coherence tomography (OCT) for a clear illustration of the enamel damage in a vertical plane. The procedure showed the entire surface of the tissue and allowed for the subsequent comparative analysis of changes in its structure. The 3D-OCT device, in addition to $\mathrm{CT}$, has a coupled digital camera with a resolution of 16.2 Mpix, which provides highly accurate images of the test area with 20 -fold zoom without a loss in image quality. The technology of Fourier Domain OCT (S-OCT), which uses spectral analysis, provides very quick scanning $(27,000$ A-scans/s), a high axial resolution of $5 \mu \mathrm{m}$ and a horizontal resolution of $20 \mu \mathrm{m}$. The use of a pulsed light source, which is a superelectroluminescent diode (SLED) in the OCT, allows for better detection of low-contrast centers. The wavelength is $840 \mathrm{~nm}$ and the half-width is $50 \mathrm{~nm}$. The 3D OCT-2000 has a scanning range of $6 \times 6 \mathrm{~mm}$ horizontally and $2.3 \mathrm{~mm}$ into the tissue. It is a device designed for ophthalmic diagnostics, whose system enables the virtual segmentation of the retina into layers, allowing for the assessment of the photoreceptors and pigment epithelium. The wavelength of $840 \mathrm{~nm}$ and the depth of penetration into the tissue also allow for imaging of the tooth enamel tissue through its entire thickness. It was possible to obtain accurate scans of the surface and enamel structure of the teeth with appropriate repeatability during 3 examinations owing to a special matrix made for each tooth. The matrix allowed for repeatable tooth positioning in the frontal, sagittal and horizontal plane relative to the optical axis of the OCT. The matrix was made of c-silicone Zetalabor hard 85 Shore A (Zhermack, Badia Polesine, Italy), on the basis of the tooth impression in the long axis, so that the vestibular surface of the crown remained above the silicone. The support for the silicone was a mold with an attachment fixed with respect to the optical axis of the OCT.

Fourier Domain OCT technology (S-OCT) allows for high-resolution spectral analysis, greater than $5 \mu \mathrm{m}$ axially and $20 \mu \mathrm{m}$ horizontally, and a quick scan of 27,000 A-scans/s. A 2-dimensional tomographic scan of the tooth is composed of 3 types of scans: A, B and C. Scan A measures the axial penetration depth of light in comparison to the reflectance curve. Scan B gives sagittal scans of the object and scan $\mathrm{C}$ provides lateral scanning images at

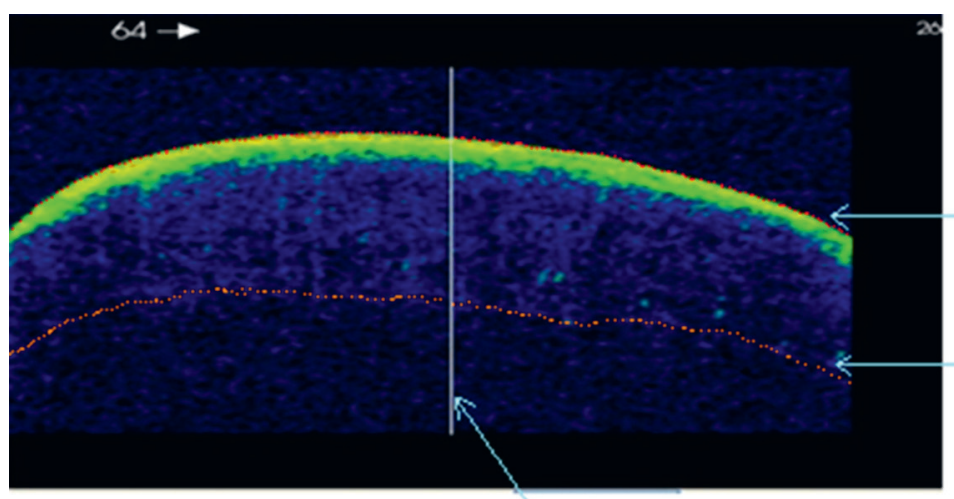

Fig. 2A. The axial aspect of the scan presented in Fig. 1, the A scan

1 - the outer layer of the enamel; 2 - the inner layer of the enamel; 3 - the axial plane in relation to which the scan 


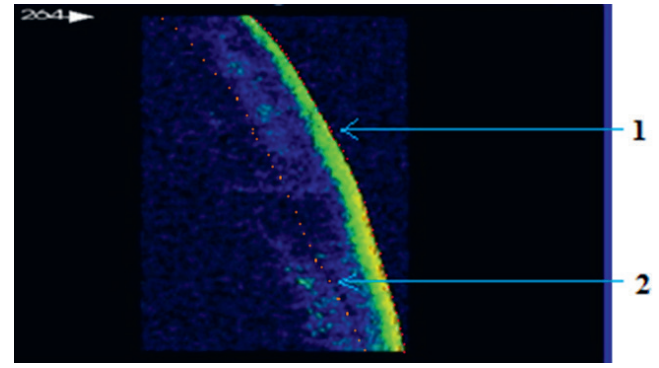

Fig. 2B. The sagittal aspect of the scan presented in Fig. 1, the B scan

1 - the outer layer of the enamel; 2 - the inner layer of the enamel.

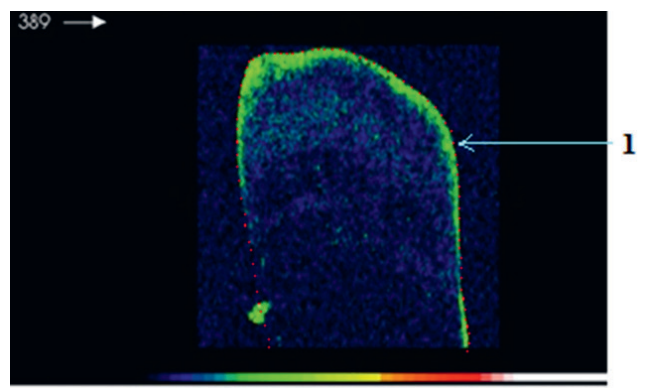

Fig. 2C. Coronal lateral scanning at a constant depth of the tooth presented in Fig. 1, the C scan

1 - the contour of a tooth at the 389 layer of the enamel tomographic scan.

a constant depth. Figures 1, 2A, 2B, and 2C show examples of the individual scans of the tooth.

The resulting OCT scans were subjected to an expert IT analysis. Image pre-processing involved automatic reading of the order of OCT images from the source file with the "fds file extension, allowing for the development of matrices of individual images.

The IT analysis, which was performed owing to a specially developed algorithm, was accurately described and published previously. ${ }^{14}$ The algorithm allowed for an automatic measurement of every tooth's enamel thickness before and after treatment. The determination of enamel thickness was possible because the algorithm automatically determined the position of both the outer and inner enamel layers directly in the image. In this manner, 20,000 scans were measured.

The results obtained in the study were statistically analyzed. The Shapiro-Wilk test was used to verify the hypothesis of normality of the variable distribution. To verify the hypothesis of the existence and non-existence of differences between the mean values for the independent variables, the median test and the Mann-Whitney U test were used. To verify the hypothesis of the existence or non-existence of differences between the mean values for the dependent variables, the Friedman two-way analysis of variance (ANOVA) and Wilcoxon matched pairs signed ranks tests were used. In order to assess the correlation between saccadic and qualitative variables, the $\chi^{2}$ test of independence, the $\chi^{2}$ test of independence with Yates's correction and the Fisher's exact test were used. Maxwell's general principle was followed when using this type of tests. The diversity of many variables in the categories determined by qualitative factors was analyzed using the analysis of variance/ analysis of covariance (ANOVA/ANCOVA) models of univariate analysis of variance. When verifying all hypotheses, the level of significance was set at $\mathrm{p}=0.05$.

\section{Results}

The $1^{\text {st }}$ step in the analysis was to measure the enamel thickness before the orthodontic treatment in all of the test samples. The calculation of the average, minimum, and maximum enamel thickness before the orthodontic treatment and the average, minimum and maximum enamel

Table 1. The characteristics of the variables obtained

\begin{tabular}{|c|c|c|c|c|c|c|c|c|c|c|}
\hline Variables & $\mathrm{n}$ & M & $\mathrm{Me}$ & Min & $\operatorname{Max}$ & Q1 & Q3 & $\mathrm{R}$ & SD & $p$-value \\
\hline I_Avg & 180 & 564.53 & 539.85 & 257.50 & $1,093.05$ & 476.53 & 643.75 & 167.22 & 137.30 & 0.0003 \\
\hline I_Min & 180 & 183.14 & 185.00 & 0.00 & 400.00 & 140.00 & 245.00 & 105.00 & 83.23 & 0.0042 \\
\hline I_Max & 180 & $1,515.91$ & $1,297.50$ & 600.00 & $4,255.00$ & $1,015.00$ & $1,900.00$ & 885.00 & 700.86 & 2.1865 \\
\hline I_Stdev & 180 & 201.22 & 163.84 & 57.95 & 740.54 & 118.66 & 226.71 & 108.05 & 126.67 & 1.3077 \\
\hline V_Avg & 180 & 470.85 & 447.85 & 172.14 & 844.79 & 369.96 & 564.13 & 194.16 & 130.87 & 2.2849 \\
\hline V_Min & 180 & 130.27 & 135.00 & 0.00 & 360.00 & 80.00 & 185.00 & 105.00 & 76.77 & 0.0023 \\
\hline V_Max & 180 & $1,098.84$ & $1,037.50$ & 450.00 & $2,755.00$ & 825.00 & $1,280.00$ & 455.00 & 424.24 & 1.3652 \\
\hline V_StDev & 180 & 149.46 & 130.94 & 35.11 & 618.01 & 92.91 & 185.42 & 92.51 & 87.49 & 2.2893 \\
\hline Dif_Avg & 180 & 93.67 & 67.72 & -142.77 & 563.03 & 29.20 & 150.83 & 121.62 & 100.24 & 1.0034 \\
\hline Dif_Min & 180 & 52.87 & 50.00 & -185.00 & 220.00 & 15.00 & 85.00 & 70.00 & 53.02 & 0.0001 \\
\hline Dif_Max & 180 & 417.06 & 197.50 & $-1,415.00$ & $3,215.00$ & 25.00 & 685.00 & 660.00 & 636.66 & 1.3414 \\
\hline
\end{tabular}

$\mathrm{n}$ - number of samples; M - arithmetic mean; Me - median; Min-Max - range of variation; Q1 - 1st quartile; Q3 - $3^{\text {rd }}$ quartile; $\mathrm{R}$ - interquartile range; SD - standard deviation; I_Avg - average enamel thickness before the orthodontic treatment; I_Min - minimum enamel thickness before the orthodontic treatment; I_Max - maximum enamel thickness before the orthodontic treatment; $\vee \_A v g$ - average enamel thickness prior to orthodontic treatment; V_Min - minimum enamel thickness prior to orthodontic treatment; $V_{-}$Max - maximum enamel thickness prior to orthodontic treatment;

Dif_Avg - difference in average enamel thickness prior to orthodontic treatment and after its completion; Dif_Min - difference in minimum enamel thickness prior to orthodontic treatment and after its completion; Dif_Max - difference in maximum enamel thickness prior to orthodontic treatment and after its completion. 
thickness, after the orthodontic treatment was conducted. All of the outcomes are presented in Table 1.

By using the metal brackets, the average thickness of the enamel after the end of treatment (V_Avg) was $487.05 \mu \mathrm{m}$, the minimum (V_Min) was $125.41 \mu \mathrm{m}$ and the maximum (V_Max) was $1046.50 \mu \mathrm{m}$. To find the differences between the thickness of the initial and final values (before and after treatment), the 2 equitable values were subtracted. By those means, the variables Dif_Avg (difference in average enamel thickness prior to orthodontic treatment and after its completion), Dif_Min (difference in minimum enamel thickness prior to orthodontic treatment and after its completion) and Dif_Max (difference in maximum enamel thickness prior to to orthodontic treatment and after its completion) were achieved. All of the described variables are presented in Table 2 . The average difference (Dif_Avg) between the thickness of the enamel before and after orthodontic treatment using the metal brackets was $63.15 \mu \mathrm{m}$ and was statistically lower in comparison with ceramic ( $<<0.018)$ and composite brackets $(\mathrm{p}<0.006)$. Statistical analysis confirmed that the thickness of the enamel varies least using metal brackets.

The average thickness of the enamel after treatment with ceramic brackets (V_Avg) was $461.00 \mu \mathrm{m}$, the minimum

Table 2. Thickness of the vestibular enamel $[\mu \mathrm{m}]$ after the orthodontic treatment in the metal bracket group

\begin{tabular}{|c|c|c|c|c|c|c|c|c|c|}
\hline Variables & $\mathrm{n}$ & M & $\mathrm{Me}$ & Min & $\operatorname{Max}$ & Q1 & Q3 & $\mathrm{R}$ & SD \\
\hline V_Avg & 60 & 487.05 & 460.82 & 259.16 & 844.79 & 379.82 & 565.94 & 186.12 & 137.13 \\
\hline V_Min & 60 & 125.41 & 132.50 & 0.00 & 360.00 & 75.00 & 177.50 & 102.50 & 84.14 \\
\hline V_Max & 60 & $1,046.50$ & $1,010.00$ & 540.00 & $2,075.00$ & $8,300.00$ & $1,210.00$ & 380.00 & 303.21 \\
\hline Dif_Avg & 60 & 63.15 & 39.11 & -142.77 & 286.02 & 22.88 & 113.18 & 90.30 & 73.09 \\
\hline Dif_Min & 60 & 51.25 & 45.00 & -80.00 & 220.00 & 10.00 & 72.50 & 62.50 & 54.52 \\
\hline Dif_Max & 60 & 485.83 & 185.00 & -915.00 & $3,215.00$ & 47.50 & 740.00 & 692.50 & 752.51 \\
\hline
\end{tabular}

$\mathrm{n}$ - number of samples; $\mathrm{M}$ - arithmetic mean; Me - median; Min-Max - range of variation; Q1 - $1^{\text {st }}$ quartile; Q3 - $3^{\text {rd }}$ quartile; R - interquartile range; SD - standard deviation; $V$ _Avg - average enamel thickness prior to orthodontic treatment; $V$ _Min - minimum enamel thickness prior to orthodontic treatment; V_Max - maximum enamel thickness prior to orthodontic treatment; Dif_Avg - difference in average enamel thickness prior to orthodontic treatment and after its completion; Dif_Min - difference in minimum enamel thickness prior to orthodontic treatment and after its completion;

Dif_Max - difference in maximum enamel thickness prior to orthodontic treatment and after its completion.

Table 3. Thickness of the vestibular enamel $[\mu \mathrm{m}]$ after the orthodontic treatment in the ceramic bracket group

\begin{tabular}{|l|c|c|c|c|c|c|c|c|c|}
\multicolumn{1}{|c|}{ Variables } & $\mathrm{n}$ & $\mathrm{M}$ & Me & Min & Max & Q1 & Q3 & R \\
\hline V_Avg & 60 & 461.44 & 454.39 & 269.35 & 744.30 & 375.32 & 542.99 & 202.88 & 143.29 \\
\hline V_Min & 60 & 150.90 & 150.00 & 0.00 & 310.00 & 100.00 & 200.00 & 105.00 \\
\hline V_Max & 60 & $1,077.45$ & $1,005.00$ & 450.00 & $2,640.00$ & 810.00 & $1,220.00$ & 525.57 \\
\hline Dif_Avg & 60 & 111.14 & 81.53 & -53.98 & 563.03 & 30.68 & 153.72 & 119.33 & 96.04 \\
\hline Dif_Min & 60 & 44.01 & 35.00 & -185.00 & 200.00 & 5.00 & 80.00 & 80.00 \\
\hline Dif_Max & 60 & 486.55 & 270.00 & -595.00 & $2,200.00$ & 60.00 & 935.00 \\
\hline
\end{tabular}

$\mathrm{n}$ - number of samples; $\mathrm{M}$ - arithmetic mean; Me - median; Min-Max - range of variation; Q1 - $1^{\text {st }}$ quartile; Q3 - $3^{\text {rd }}$ quartile; R - interquartile range; SD - standard deviation; $V_{\_}$Avg - average enamel thickness prior to orthodontic treatment; $V_{\text {_Min }}$ - minimum enamel thickness prior to orthodontic treatment; V_Max - maximum enamel thickness prior to orthodontic treatment; Dif_Avg - difference in average enamel thickness prior to orthodontic treatment and after its completion; Dif_Min - difference in minimum enamel thickness prior to orthodontic treatment and after its completion; Dif_Max - difference in maximum enamel thickness prior to orthodontic treatment and after its completion.

Table 4. Thickness of the vestibular enamel $[\mu \mathrm{m}]$ after the orthodontic treatment in the composite bracket group

\begin{tabular}{|c|c|c|c|c|c|c|c|c|c|}
\hline Variables & $n$ & M & $\mathrm{Me}$ & Min & Max & Q1 & Q3 & $\mathrm{R}$ & SD \\
\hline V_Avg & 60 & 464.73 & 418.98 & 172.14 & 774.27 & 354.87 & 589.92 & 167.67 & 116.14 \\
\hline V_Min & 60 & 115.38 & 115.00 & 0.00 & 250.00 & 70.00 & 170.00 & 100.00 & 74.75 \\
\hline V_Max & 60 & 1,167.23 & $1,075.00$ & 465.00 & $2,755.00$ & 850.00 & $1,310.00$ & 410.00 & 438.62 \\
\hline Dif_Avg & 60 & 105.45 & 95.45 & -138.47 & 461.71 & 37.12 & 165.78 & 123.03 & 113.02 \\
\hline Dif_Min & 60 & 62.69 & 60.00 & -50.00 & 180.00 & 30.00 & 95.00 & 75.00 & 55.63 \\
\hline Dif_Max & 60 & 288.38 & 125.00 & $-1,415.00$ & $1,505.00$ & 10.00 & 515.00 & 875.00 & 632.78 \\
\hline
\end{tabular}

n - number of samples; M - arithmetic mean; Me - median; Min-Max - range of variation; Q1 - $1^{\text {st }}$ quartile; Q3 - $3^{\text {rd }}$ quartile; R - interquartile range; SD - standard deviation; $V \_$Avg - average enamel thickness prior to orthodontic treatment; $V_{\text {_Min }}$ - minimum enamel thickness prior to orthodontic treatment; V_Max - maximum enamel thickness prior to orthodontic treatment; Dif_Avg - difference in average enamel thickness prior to orthodontic treatment and after its completion; Dif_Min - difference in minimum enamel thickness prior to orthodontic treatment and after its completion; Dif_Max - difference in maximum enamel thickness prior to orthodontic treatment and after its completion. 
(V_Min) was $150.90 \mu \mathrm{m}$ and the maximum (V_Max) was $1077.45 \mu \mathrm{m}$. The average difference (Dif_Avg) between the thickness of the enamel at the beginning and at the end of treatment amounted to $111.14 \mu \mathrm{m}$. The differences between the initial and final values were found in the same manner as in the metal bracket group. All of the variables are presented in Table 3 .

In the groups treated with composite brackets, the thickness of the enamel after the treatment was $464.73 \mu \mathrm{m}$ (V_Avg), $115.38 \mu \mathrm{m}$ (V_min) and 1,167.23 $\mu \mathrm{m}$ (V_max). The average loss of enamel was $105.45 \mu \mathrm{m}$. The differences between the initial and final values were found in the same manner as in the metal and ceramic bracket groups. All of the variables are presented in Table 4. Enamel thickness changes in the composite and ceramic bracket groups were not statistically significant $(\mathrm{p}<0.005)$.

\section{Discussion}

The presented results show that the enamel thickness after completed treatment and its possible damage is dependent on the type of orthodontic bracket. So far, evaluation of the full tissue thickness has been difficult to carry out, so there are not many publications to refer to when discussing the results. To date, only 2 recent publications have revealed significant agreement in the potential of OCT as a clinical tool to effectively measure the whole enamel layer thickness. ${ }^{15,16}$ Some publications have acknowledged the risk of using ceramic brackets and Suliman et al. widened the available knowledge on the topic by evaluating 2 types of these brackets, in which polycrystalline brackets were found to be more dangerous to the enamel structure. ${ }^{17-19}$

A number of studies evaluating the loss of enamel thickness and surface damage following the removal of brackets have been published, in which the measuring tools were a planer surfometer and profilometer. ${ }^{20-23}$ These methods allow for a small number of single tooth surface measurements, while the studies carried out with a profilometer and surface analyzer do not show the examined structure. The newest methods of tooth enamel analysis include assessment by means of an atomic force microscope (AFM). This method shows promising results in depicting the enamel surface, but still it does not allow to analyze the whole tissue. ${ }^{24-27}$ These methods, however, do not enable automatic, quantitative measurement of the enamel thickness in automatic comparison of image groups. This is the case, where comparisons between specific areas of the tooth enamel were made manually in OCT images. ${ }^{28}$ Automatic measurement was presented in the article. ${ }^{29}$ However, the article concerns polarization-sensitive optical coherence tomography (PS-OCT) and is not related to the problem of overlapping individual images in the subsequent processing stages of the tooth, as shown in this paper.

It can be assumed that residues which are invisible after polishing the local resin may stay unrecognized and may be confused with enamel damage. Such phenomena can have a major impact on the results of the examination. The actual size of the resulting enamel damage can be diametrically different than previously supposed. In addition, tooth surfaces which are not fully flat make it difficult to carry out meaningful analysis. Only optical sensors and scanning lasers can allow accurate volume and vertical measurements of the enamel..$^{30}$ Recently, the use of scanning electron microscope (SEM) after bracket debonding has shown accuracy in conceptualizing the proper protocol in removing the bonding remnants and in evaluating the eventual damage after the finished treatment. ${ }^{31-33}$ The distinction between the loss of enamel and residual resins is only credible in the 3-dimensional evaluations that have so far only been possible with laser scanning techniques. ${ }^{34}$

A new application of the abovementioned device was employed to evaluate the diversity of the image depending on the size and depth of the generated pores of the enamel, which affect the propagation of light waves in the tissue and the appropriate image registration. Automatic analysis of tooth enamel thickness as a tool for digital intraoral imaging provides a number of possibilities. These include area analysis of the enamel thickness (for each individual tooth area separately) and enamel texture analysis. Imaging and quantitative measurement of the enamel structure before the installation of braces and after their removal enables the exposure of the extent of the tooth tissue damage depending on the brackets used and on the method of attachment. Such method makes it possible to deduce which bracket material and which installation technique are the safest for tooth enamel.

The OCT capabilities commonly applied in many fields of medicine (such as ophthalmology) are not yet fully used in dentistry, mainly due to the low availability of customized intraoral equipment and the insufficient range of OCT rays, which penetrate into the tissue to a depth of only a few millimeters, depending on the apparatus type. Lesions within the tooth tissue usually reach deeper, and are often measured in centimeters, which makes it necessary to perform hundreds or even thousands of scans to illustrate the entire lesion. To maximize the efficiency of the dental diagnostic OCT, the wavelengths of light responsible for generating the image should be subjected to testing. In the nearinfrared light range, the central wavelength determines the maximum depth of penetration into the tissue due to scattering and absorption properties. ${ }^{35} \mathrm{~A}$ wavelength below $1000 \mathrm{~nm}$ provides the greatest imaging efficiency because the light scattering properties are similar to the size of the tissue particles. Hydrated tissues dissipate much more energy than hard tissues containing a small percentage of water. For this reason, universal dental OCT should offer the possibility to control the wavelength depending on the type of tissue tested. A different wavelength must be used to image the periodontal and tooth tissue per se.

Another problem arising in dental diagnosis is the quality of individual teeth. The enamel can vary in its structure 
in a single subject. Likewise, dental fillings or prosthetic materials having a different composition reflect or absorb light to varying degrees, which has a decisive effect on the image quality and the correct interpretation of it. Materials whose reflectance index is similar to that of the background will give a similar image. In addition to image quality, the ability to perform objective measurements of the obtained scans is very important. To date, publications have been mainly focused on the ability to obtain images of individual structures and on their acquisition rate, which is especially important in in vivo studies. We attempted to develop an algorithm for rapid and accurate measurements of tooth tissues. The presented algorithm is only one way to complete the described task. Other authors are already interested in the topic of OCT imaging in the field of orthodontics, proving our hypothesis that OCT should be incorporated into clinical diagnostics..$^{19,36-40}$

\section{Conclusions}

Optical coherence tomography is an effective diagnostic tool to evaluate the thickness of the enamel tissue before and after orthodontic treatment. It provides tissue sections in a non-contact and non-invasive manner and allows for real-time tissue imaging in situ, without the need for histological procedures or, especially, the use of X-rays. Therefore, it is suitable for dental and orthodontic diagnostics in patients of any age. It is first and foremost important in pediatric patients, where the safe X-ray dose has not been precisely determined. Also, in this group of patients, orthodontic treatment is often performed. Considering the structure of young teeth susceptible to damage caused by plaque, caries and acids, it is very important in clinical practice to examine the structure of the enamel before starting treatment, especially because changes in the enamel layer thickness after orthodontic treatment have proved to be determined by the type of material which the orthodontic bracket is made of. This analysis informs orthodontists as to which braces should be used in specific cases. The method has great applications in clinical practice, which will be shown in an upcoming publication.

\section{References}

1. Huang D, Swanson EA, Lin CP, et al. Optical coherence tomography. Science. 1991;254(5035):1178-1181.

2. Fercher $A F$, Hitzenberger $C K$, Drexler W, Kamp G, Sattmann H. In vivo optical coherence tomography. Am J Ophtalmol. 1993;116(1):113-114.

3. Fercher AF, Hitzenberger CK, Kamp G, El-Zaiat SY. Measurement of intraocular distances by backscattering spectral interferometry. Opt Commun. 1995;117(1-2):30-43.

4. Simon JC, Kang $\mathrm{H}$, Staninec $\mathrm{M}$, et al. Near-IR and CP-OCT imaging of suspected occlusal caries lesions. Lasers Surg Med. 2017;49(3):215-224.

5. Maia AM, de Freitas AZ, de L Campello S, Gomes AS, Karlsson L. Evaluation of dental enamel caries assessment using quantitative light induced fluorescence and optical coherence tomography. J Biophotonics. 2016;9(6):596-602.
6. Horie K, Shimada Y, Matin K, et al. Monitoring of cariogenic demineralization at the enamel-composite interface using swept-source optical coherence tomography. Dent Mater. 2016;32(9):1103-1112.

7. Damodaran V, Ranga RS, Vasa NJ. Optical coherence tomography based imaging of dental demineralisation and cavity restoration in $840 \mathrm{~nm}$ and $1310 \mathrm{~nm}$ wavelength regions. Opt Lasers Eng. 2016;59:14.

8. Adegun OK, Tomlins PH, Hagi-Pavli E, Bader DL, Fortune F. Quantitative optical coherence tomography of fluid-filled oral mucosal lesions. Lasers Med Sci. 2013;28(5):1249-55.

9. Sanda M, Shiota M, Imakita C, Sakuyama A, Kasugai S, Sumi Y. The effectiveness of optical coherence tomography for evaluating peri-implant tissue: A pilot study. Imaging Sci Dent. 2016;46(3): 173-178.

10. Adegun OK, Tomlins PH, Hagi-Pavli E, et al. Quantitative analysis of optical coherence tomography and histopathology images of normal and dysplastic oral mucosal tissues. Lasers Med Sci. 2012;27(4): 795-804.

11. Kim SH, Kang SR, Park HJ, Kim JM, Yi WJ, Kim TI. Improved accuracy in periodontal pocket depth measurement using optical coherence tomography. J Periodontal Implant Sci. 2017;47(1):13-19.

12. Fernandes LO, Mota CC, de Melo LS, da Costa Soares MUS, da Silva Feitosa D, Gomes ASL. In vivo assessment of periodontal structures and measurement of gingival sulcus with optical coherence tomography: A pilot study. J Biophotonics. 10(6-7):862-869.

13. Kim JM, Kang SR, Yi WJ. Automatic detection of tooth cracks in optical coherence tomography images. J Periodontal Implant Sci. 2017;47(1): $41-50$.

14. Koprowski R, Machoy M, Woźniak K, Wróbel Z. Automatic method of analysis of OCT images in the assessment of the tooth enamel surface after orthodontic treatment with fixed braces. Biomed Eng Online. 2014;13:48.

15. Algarni A, Kang H, Fried D, Eckert GJ, Hara AT. Enamel thickness determination by optical coherence tomography: In vitro validation. Caries Res. 2016;50(4):400-406.

16. Seeliger J, Machoy M, Koprowski R, et al. Enamel thickness before and after orthodontic treatment analysed in optical coherence tomography. Biomed Res Int. 2017;2017:8390575.

17. Suliman SN, Trojan TM, Tantbirojn D, Versluis A. Enamel loss following ceramic bracket debonding: A quantitative analysis in vitro. Angle Orthod. 2015;85(4):651-656.

18. Bernard-Granger C, Gebeile-Chauty S. Enamel cracks: Influence of orthodontic process [in French]. Orthod Fr. 2014;85(3):245-251.

19. Leão Filho JC, Braz AK, de Araujo RE, Tanaka OM, Pithon MM. Enamel quality after debonding: Evaluation by optical coherence tomography. Braz Dent J. 2015;26(4):384-389.

20. Davis VA, Staley RN, Bigelow HF, Jakobsen JR. Remnant amount and cleanup for 3 adhesives after debracketing. Am J Orthod Dentofacial Orthop. 2002;121(3):291-296.

21. Hosein I, Sherriff M, Ireland AJ. Enamel loss during bonding, debonding, and cleanup with use of a self-etching primer. Am J Orthod Dentofacial Orthop. 2004;126(6):717-724.

22. Eliades T, Gioka C, Eliades G, Makou M. Enamel surface roughness following debonding using two resin grinding methods. Eur J Orthod. 2004;26(3):333-338.

23. Kim SS, Park WK, Son WS, Ahn HS, Ro JH, Kim YD. Enamel surface evaluation after removal of orthodontic composite remnants by intraoral sandblasting: A 3-dimensional surface profilometry study. Am J Orthod Dentofacial Orthop. 2007;132(1):71-76.

24. Finke M, Parker DM, Jandt KD. Influence of soft drinks on the thickness and morphology of in situ acquired pellicle layer on enamel. J Colloid Interface Sci. 2002;251(2):263-270.

25. Watari F. In situ quantitative analysis of etching process of human teeth by atomic force microscopy. J Electron Microsc (Tokyo). 2005;54 (3):299-308,

26. Mohebi S, Shafiee HA, Ameli N. Evaluation of enamel surface roughness after orthodontic bracket debonding with atomic force microscopy. Am J Orthod Dentofacial Orthop. 2017;151(3):521-527.

27. Lorenzo MC, Portillo M, Moreno P, et al. Ultrashort pulsed laser conditioning of human enamel: In vitro study of the influence of geometrical processing parameters on shear bond strength of orthodontic brackets. Lasers Med Sci. 2015;30(2):891-900. 
28. Wilder-Smith $\mathrm{CH}$, Wilder-Smith $\mathrm{P}$, Kawakami-Wong $\mathrm{H}$, Voronets J, Osann K, Lussi A. Quantification of dental erosions in patients with GERD using optical coherence tomography before and after double-blind, randomized treatment with esomeprazole or placebo. Am J Gastroenterol. 2009;104(11):27-88.

29. Le $M H$, Darling CL, Fried D. Automated analysis of lesion depth and integrated reflectivity in PS-OCT scans of tooth demineralization. Lasers Surg Med. 2010;42(1):42-62.

30. Oliver RG, Griffiths J. Different techniques of residual composite removal following debonding: Time taken and surface enamel appearance. Br J Orthod. 1992;19(2):131-137.

31. Vidor MM, Felix RP, Marchioro EM, Hahn L. Enamel surface evaluation after bracket debonding and different resin removal methods. Dental Press J Orthod. 2015;20(2):61-67.

32. Faria-Júnior ÉM, Guiraldo RD, Berger SB, et al. In-vivo evaluation of the surface roughness and morphology of enamel after bracket removal and polishing by different techniques. Am J Orthod Dentofacial Orthop. 2015;147(3):324-329.

33. Fan XC, Chen L, Huang XF. Effects of various debonding and adhesive clearance methods on enamel surface: An in vitro study. BMC Oral Health. 2017;17(1):58.

34. Al Shamsi AH, Cunningham JL, Lamey PJ, Lynch E. Three-dimensional measurement of residual adhesive and enamel loss on teeth after debonding of orthodontic brackets: An in vitro study. Am J Orthod Dentofacial Orthop. 2007;131(3):301e9-e15.
35. Wang LV, Wu HI. Biomedical Optics. Hoboken, NJ: John Wiley \& Sons; 2007.

36. Baek JH, Na J, Lee BH, Choi E, Son WS. Optical approach to the periodontal ligament under orthodontic tooth movement: A preliminary study with optical coherence tomography. Am J Orthod Dentofacial Orthop. 2009;135(2):252-259.

37. Garcez AS, Suzuki SS, Ribeiro MS, Mada EY, Freitas AZ, Suzuki H. Biofilm retention by 3 methods of ligation on orthodontic brackets: A microbiologic and optical coherence tomography analysis. Am J Orthod Dentofacial Orthop. 2011;140(4):e193-198.

38. Pithon MM, Santos Mariana de J, de Souza CA, et al. Effectiveness of fluoride sealant in the prevention of carious lesions around orthodontic brackets: An OCT evaluation. Dental Press J Orthod. 2015;20 (6):37-42.

39. Nee A, Chan K, Kang H, Staninec M, Darling CL, Fried D. Longitudinal monitoring of demineralization peripheral to orthodontic brackets using cross polarization optical coherence tomography. J Dent. 2014;42(5):547-555.

40. Leão Filho JC, Braz AK, de Souza TR, de Araujo RE, Pithon MM, Tanaka OM. Optical coherence tomography for debonding evaluation: An in-vitro qualitative study. Am J Orthod Dentofacial Orthop. 2013; 143(1):61-68 